\title{
Satellite-derived land surface parameters for mesoscale modelling of the Mexico City basin
}

\author{
B. de Foy ${ }^{1, *}$, L. T. Molina ${ }^{1, *}$, and M. J. Molina ${ }^{1}$ \\ ${ }^{1}$ Department of Earth, Atmospheric and Planetary Sciences, Massachusetts Institute of Technology, USA \\ *now at: Molina Center for Energy and the Environment, CA, USA
}

Received: 7 September 2005 - Published in Atmos. Chem. Phys. Discuss.: 12 October 2005

Revised: 31 January 2006 - Accepted: 21 February 2006 - Published: 25 April 2006

\begin{abstract}
Mesoscale meteorological modelling is an important tool to help understand air pollution and heat island effects in urban areas. Accurate wind simulations are difficult to obtain in areas of weak synoptic forcing. Local factors have a dominant role in the circulation and include land surface parameters and their interaction with the atmosphere. This paper examines an episode during the MCMA-2003 field campaign held in the Mexico City Metropolitan Area (MCMA) in April of 2003. Because the episode has weak synoptic forcing, there is the potential for the surface heat budget to influence the local meteorology. High resolution satellite observations are used to specify the land use, vegetation fraction, albedo and surface temperature in the MM5 model. Making use of these readily available data leads to improved meteorological simulations in the MCMA, both for the wind circulation patterns and the urban heat island. Replacing values previously obtained from land-use tables with actual measurements removes the number of unknowns in the model and increases the accuracy of the energy budget. In addition to improving the understanding of local meteorology, this sets the stage for the use of advanced urban modules.
\end{abstract}

\section{Introduction}

With ever more people living in cities and ever larger urban areas, the impact of urbanisation on local climate is becoming increasingly important to health and comfort as well as to planning of city systems. Arnfield (2003) and Britter and Hanna (2003) review recent urban climate research, highlighting the formation of the Urban Heat Island (UHI), impacts on the exchanges of heat and water at the surface and

Correspondence to: B. de Foy

(bdefoy@mce2.org ) modifications of the dispersion of gases and aerosols in the atmosphere.

Mesoscale modelling is an important tool in analysing and understanding these changes, provided that accurate simulations can be obtained. Data assimilation (Stauffer and Seaman, 1994) has proved instrumental in improving certain model results. There are however situations where it is difficult to apply it successfully (Daley, 1991). This is especially true when there is weak synoptic forcing. In these cases, the heat and moisture budget at the land surface has a much greater effect on the local meteorology.

Recently there has been development of new urban modules for use in mesoscale models, see for example Martilli et al. (2002), Dupont et al. (2004) and Otte et al. (2004). Parameterisations based on detailed data describing the land surface are used to obtain the energy and humidity fluxes at the surface. Because these data are often not known precisely, tabulated values are often used in combination with coarse land use data as a substitute.

Satellite remote sensing provides a wealth of data describing the earth surface (Townshend and Justice, 2002) and is becoming more accurate at observing the thermal properties of urban areas (Voogt and Oke, 2003) and (Dousset and Gourmelon, 2003). This can be used in the simulation of the urban climate to improve the model representation of the land surface (Jin and Shepherd, 2005). In this paper, readily available satellite data is used to improve the simulation of urban winds with the Pennsylvania State University/National Center for Atmospheric Research Mesoscale Model (MM5, Grell et al., 1995) for an episode in the Mexico City basin.

The Mexico City Metropolitan Area (MCMA) is situated inside a basin at $2240 \mathrm{~m}$ altitude and $19^{\circ} \mathrm{N}$ latitude and is surrounded by high mountains on three sides. The combination of weak winds and numerous pollutant sources leads to high levels of air pollution, as reviewed in Molina and Molina (2002). Fast and Zhong (1998) describe the complex meteorological conditions found in the basin along with

Published by Copernicus GmbH on behalf of the European Geosciences Union. 


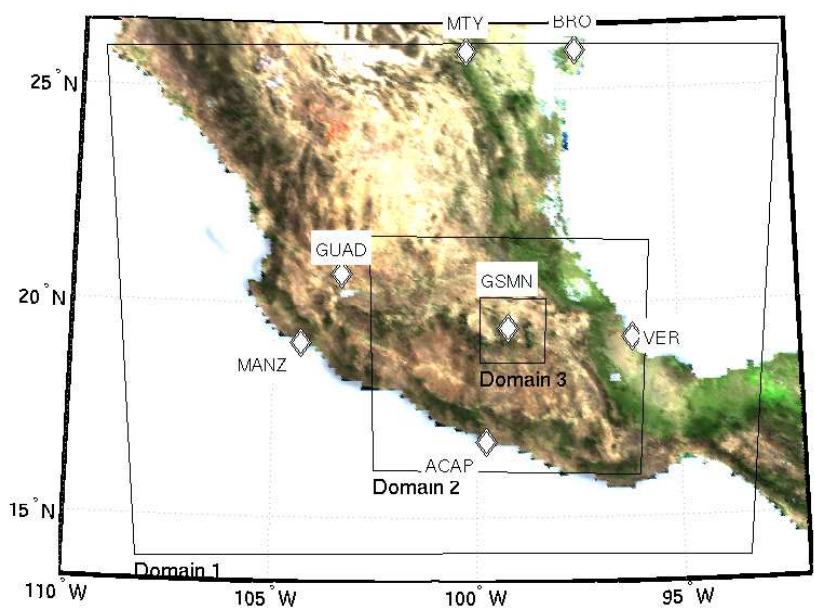

Fig. 1. MM5 Domains overlayed on a satellite picture of Mexico from the time of the campaign. Circles represent Radiosonde locations: Mexico City (GSMN), Acapulco (ACAP), Veracruz (VER), Monterrey (MTY), Guadalajara (GUAD), Manzanillo (MANZ) and Brownsville (BRO).

the difficulty in obtaining accurate simulations. Whiteman et al. (2000) and Doran and Zhong (2000) analyse the growth of the boundary layer and the wind jets found in the basin. The timing and extent of these features is dependent on the thermal balance between the basin and the surrounding areas. de Foy et al. (2005) analyse the meteorological conditions occurring during the MCMA-2003 field campaign in April 2003. Each day of the campaign was classified into one of three episode types: "O3-South", "Cold Surge" and "O3-North". The "O3-South" days have the weakest synoptic forcing and therefore the greatest influence of local thermodynamics on the wind patterns.

Urban turbulent heat flux measurements have been reviewed by Grimmond and Oke (2002) and for Mexico City by Tejeda-Martinez and Jauregui-Ostos (2005). Oke et al. (1999) reported measurements in the MCMA during the dry seasons showing low latent heat fluxes with the dominant energy budget term being ground fluxes. Jauregui and Tejeda (1997) found that there is a very frequent nocturnal heat island with intensities of 4-5 $\mathrm{K}$ and a less frequent daytime effect.

MM5 has a five layer soil temperature model with constant moisture availability (Dudhia, 1996). Chen and Dudhia (2001) added the more sophisticated NOAH model with layers for both soil temperature and moisture and a much more sophisticated treatment of thermodynamics and hydrology. Hogue et al. (2005) have evaluated this model for semiarid environments looking at the factors contributing to accurate simulations.

Mölders (2001) analyses the uncertainty in mesoscale modelling caused by surface parameters. Large impacts are found suggesting that actual parameters rather than tabulated values should be used wherever possible. Atkinson (2003) analysed the impact of surface parameters on the simulation of the urban heat island. He found that the roughness length and surface resistance to evaporation were the most important factors during the day, and anthropogenic heat flux was the most important at night.

Satellite measurements can be used to reduce the number of unknowns in the domain. Carlson et al. (1981) obtained parameters for soil moisture and thermal inertia by finding the best match between a land surface model and Advanced Very High Resolution Radiometer (AVHRR) radiant temperatures. This showed a strong decrease in latent heat fluxes over urban areas, but little change in thermal inertia. Hafner and Kidder (1999) refined the analysis with a mesoscale model and highlighted the importance of the soil heat flux, especially at night.

Vegetation fraction obtained from the normalised difference vegetation index (NDVI) have been used for global, regional and local models. Kurkowski et al. (2003) used AVHRR values in the Eta model thereby improving the surface temperature forecasts. The Moderate Resolution Imaging Spectroradiometer (MODIS) gathers data in 36 spectral bands on board the Terra (EOS AM) and Aqua (EOS PM) satellites (Townshend and Justice, 2002). Tian et al. (2004) used vegetation fields, plant types and leaf area index from MODIS in the Community Land Model to improve the simulated ground and canopy evaporation rates. Matsui et al. (2005) made use of AVHRR NDVI data in the Regional Climate Model showing the importance of land-atmosphere exchanges in the North American monsoon. At the mesoscale, Crawford et al. (2001) included vegetation fraction, albedo and leaf area index from AVHRR within MM5 and found improved accuracy of heat-wave forecasts. They highlight the potential value of satellite data in improving performance for extreme events. While these are typically events for which forecasts are most valuable, they are also the most poorly predicted events at present.

In this paper, land surface data from MODIS will be used in the MM5 model with both the NOAH and 5-Layer land surface models for an episode with weak synoptic forcing in the MCMA. Section 2 will describe the model set-up and Sect. 3 the data available for model evaluation. The soil moisture initialisation will be presented in Sect. 4 followed by the satellite parameter inputs in Sect. 5 and the tabulated values remaining in Sect. 6. The model will be evaluated against observations in Sect. 7 and statistics will be presented in Sect. 8.

\section{Model description}

The basin circulation was simulated using MM5 version 3.7.2 (Grell et al., 1995) using three nested grids with oneway nesting. The grid resolution used is 36,12 and $3 \mathrm{~km}$, with $40 \times 50,55 \times 64$ and $61 \times 61$ grid cells for domains 1 , 
2 and 3, respectively. Figure 1 shows the 3 domains on a map of Mexico. The episode simulated in this study is the first "O3-South" episode described in de Foy et al. (2005), so named because the ozone peak is in the south of the MCMA. The model was initialised on 13 April at 12:00 UTC. The first $18 \mathrm{~h}$ are used for initialisation followed by the simulation period from 14-17 April inclusive. This episode was selected because it exhibits a representative flow pattern that has been widely analysed in the past. It was dry, with no rain and few clouds thereby reducing one source of uncertainty in the model. The synoptic forcing was weak making this an ideal test case of the land surface parameters.

The initial and boundary conditions for the model were taken from the Global Forecast System (GFS, Kalnay et al., 1990) at a 3-h resolution. This model is run 4 times a day at 00, 06, 12 and 18Z. Both the analysis step and the first forecast step $3 \mathrm{~h}$ later from each run was used. GFS uses the NOAH land surface model with 2 layers at 10 and $200 \mathrm{~cm}$ which provides land surface temperature and moisture initial conditions for MM5 when run with the NOAH land surface scheme. For the 5 layer scheme, a look-up table is used to determine soil moisture based on the land-use category.

MM5 was run with the MRF boundary layer scheme, the Kain-Frisch convection scheme, simple ice microphysics and cloud radiation scheme. One way nesting was employed together with the default 23 sigma levels in the vertical. Sigma diffusion using the perturbation temperature was used for domains 1 and 2, and z-diffusion for domain 3 (Zängl et al., 2004). The topography in the model was obtained from global databases at 10 and 2 min resolution for domains 1 and 2 , and from $30 \mathrm{~s}$ data from the USGS GTOPO30 database for domain 3. Sub-grid scale topography is not taken into account. Soil type was derived from the $5 \mathrm{~min}$ resolution UN-FAO database.

It should be noted that of the recent changes to MM5, the correction of the convective velocity in the MRF scheme was particularly important in improving the morning surface wind speeds when the NOAH scheme was used. Using true horizontal diffusion (z-diffusion) for the fine domain also led to solution improvements. Recent changes were made in the NOAH surface scheme for urban land categories, resetting certain parameters that influence the latent heat flux. For the current set-up, the impact of these changes was to reduce the latent heat flux to 0 over the whole urban area. It was therefore decided to comment out the places in the code where constants are changed for urban land-use only, thereby restoring the latent heat flux to the same values as previous code versions.

The GFS analysis is already based on all available radiosonde observations. For this reason, it can be used to do four dimensional data assimilation (FDDA) above the boundary layer without further ingestion of data. When used, this was applied to domain 1 only.

Simulations will be presented using both the 5 layer soil temperature scheme and the NOAH land surface scheme. For

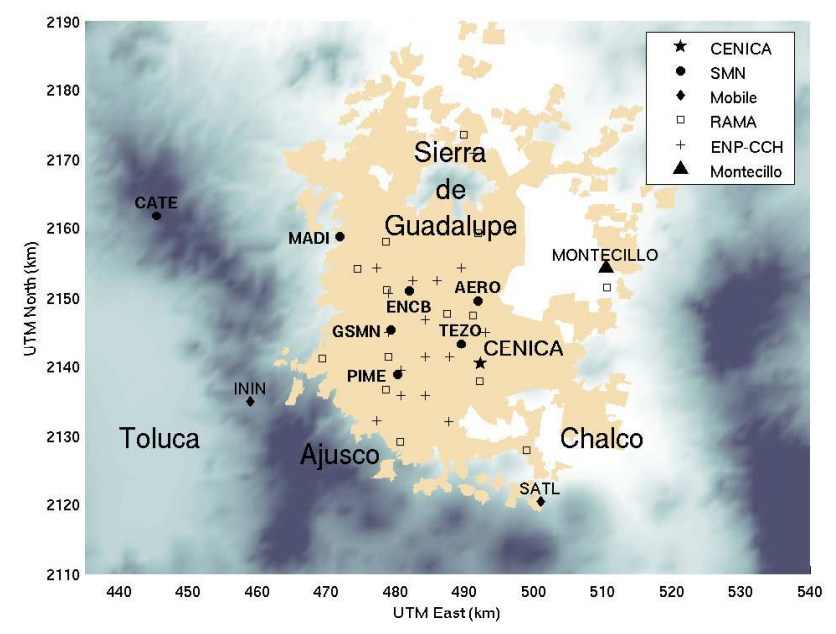

Fig. 2. Meteorological measurement locations in the Mexico City basin. The star is the CENICA supersite. Circles are National Meteorological Service surface stations: SMN Headquarters (GSMN), Escuela Nacional de Ciencias Biológicas (ENCB), Mexico International Airport (AERO), Tezontle (TEZO), Pimentel (PIME) and Presa Madín (MADI). Diamonds are temporary stations operating during the campaign: Instituto Nacional de Investigaciones Nucleares (ININ) and Santa Ana Tlacotenco (SATL). Squares are RAMA stations reporting meteorological information. Crosses are locations of the UNAM-CCA high school network. Soil temperature measurements are available at Montecillo. Urban areas of 1995 are shown in beige, shading corresponds to terrain elevation.

data analysis and comparison with observations, values from the nearest grid point were extracted with no averaging or interpolation.

\section{Measurement description}

Data for model comparisons were obtained during the MCMA-2003 field campaign which was based at the National Center for Environmental Research and Training (Centro Nacional de Investigación y Capacitación Ambiental, CENICA) super-site.

Figure 2 shows the station locations in the basin. CENICA has a meteorological monitoring station. The automatic weather stations (EHCA) are operated by the Servicio Meteorológico Nacional (SMN, see http://smn.cna.gob.mx/ productos/emas/emas.html) and report 10-min data in three hour blocks via satellite. The observations were averaged to one hour intervals for this analysis. The SMN radiosondes are launched at 12:00 UTC outside of Mexico City. The Mexico City radiosondes are launched from the SMN headquarters (GSMN), WMO ID 76679 (also MEX) which is on the western edge of the basin floor every $6 \mathrm{~h}$ at 00:00, 06:00, 12:00 and 18:00 UTC.

The Ambient Air Monitoring Network (Red Automática de Monitoreo Atmosférico, RAMA) operates 15 


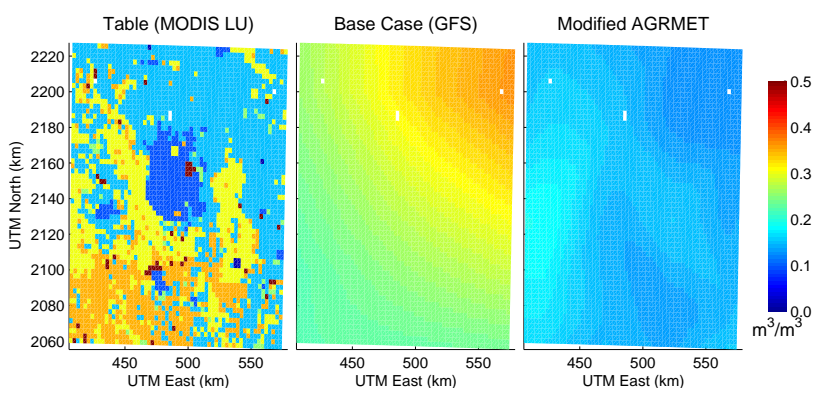

Fig. 3. Soil moisture maps for the fine domain for table values with MODIS land-use shown for reference only, base case using GFS data, and modified case using modified AGRMET data (see text for details).

meteorological stations throughout the city. Data from a further 10 stations operated in high schools throughout the MCMA by the Centro de Ciencias de la Atmósfera, Universidad Nacional Autónoma de México was available. Temporary stations were deployed during the campaign to get additional information from the boundaries. These include roof-top equipment at ININ (Instituto Nacional de Investigaciones Nucleares) and a mobile van located at Santa Ana Tlacotenco (SATL).

Finally, soil temperature measurements were made at the Montecillo campus of the Colegio de Postgraduados, Institución de Enseñanza e Investigación en Ciencias Agrícolas.

\section{Soil moisture}

Soil moisture is a determining factor in the partition between latent and sensible heat fluxes, see for example Small and Kurc (2003). Reichle et al. (2004) and Hirabayashi et al. (2003) describe the satellite measurements available and their combined use with land surface models and ground data to obtain soil moisture fields for global models. van den Hurk (2001) derive surface flux estimates by combining satellite measurements of surface temperature with a soil moisture model. Margulis and Entekhabi (2003) develop a variational data assimilation framework to improve the simulations of a coupled land surface-atmospheric boundary layer model, relying on data from a specialised field campaign. Soil moisture products are available from the Advanced Microwave Scanning Radiometer (AMSR-E) (Njoku et al., 2003). However, these are valid for a very thin layer of the surface that is not representative of the deeper moisture. In the case of Mexico this leads to extremely dry estimates and was therefore not used. Cashion et al. (2005) evaluate soil moisture from the TRMM Microwave Imager (TMI) but conclude that additional in situ data is needed when using this product.

Extensive soil moisture related data was not available for the present study and the sophisticated assimilation techniques are beyond our current scope. For base case runs, the soil moisture and temperature were interpolated from the GFS output. The modified simulations however made use of the soil moisture predicted by the Air Force Weather Agency's (AFWA) Agricultural Meteorology modelling system (AGRMET). Like the GFS, this uses the NOAH land surface model, but at a resolution of $47 \mathrm{~km}$. It is run in offline mode cycling on itself with extensive data assimilation. Schaake et al. (2004) compares the soil moisture fields from 4 different models including NOAH. The largest differences between the models were found for dry areas, suggesting that this remains an open question that will need further attention.

For Mexico, the soil moisture is strongly influenced by convective rainfall, with individual storms leading to very moist patches in dry areas lasting for several days. In particular, AGRMET simulated heavy rains on 10 April over the MCMA and the surrounding region. This was not verified by measurements and led to abnormally high soil moisture values. For this reason, the soil moisture fields from the 9 preceding days were averaged and used as an initial condition for MM5, as shown in Fig. 3. The soil moisture values that would have been obtained from using table values are also shown for comparison.

MM5-generated rainfall also had a very large impact on soil moisture. Because the exact location of rainfall is difficult to simulate accurately, and the effects on soil moisture in the model are both significant and long-lasting, it was decided to prevent time variations in the soil moisture fields in the modified MM5 runs. This removes a large area of uncertainty in the response of MM5 to the land surface parameters.

\section{Satellite land surface parameters}

\subsection{Land-use}

MM5 uses the USGS land-use maps derived from AVHRR data using one year of data from April 1992 to March 1993 (Loveland et al., 2000). The resolution for the finest domain is $1 \mathrm{~km}$. Friedl et al. (2002) derived a land-use map from MODIS data for 2001, with the same spatial resolution. This was aggregated to 36,12 and $3 \mathrm{~km}$ resolution by taking the mode for each cell except for water and urban categories. In these cases, they were attributed only if they made up more than $50 \%$ of the available points. If less than half of the cells were water or urban, then the mode of the remaining categories was used as the representative value.

Figure 4 compares the two land-use maps. The growth of the MCMA in the 9 year gap can be clearly seen, along with the expansion of neighbouring cities such as Toluca, Cuernavaca and Pachuca, and the appearance of smaller cities such as Cuautla. There is also a finer resolution of the different forest types, including different categories for the evergreen broad-leaf cells surrounding the city in the AVHRR data which are not there in reality. Shrub and grasslands are partitioned differently, with greater use of the mixed category 

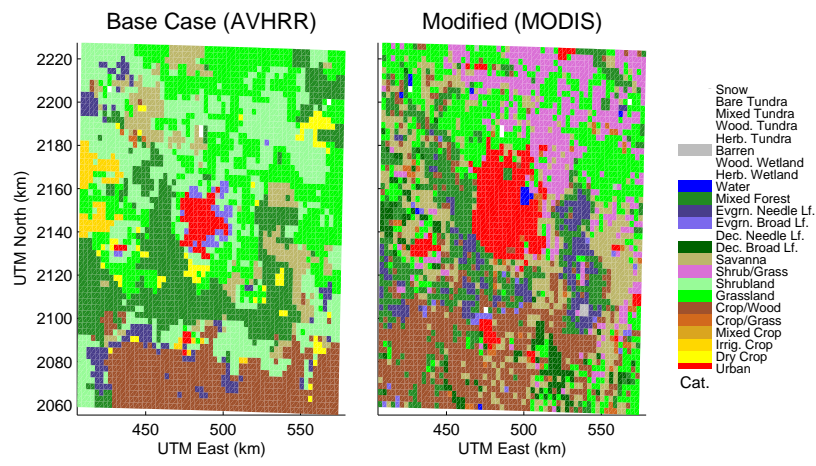

Fig. 4. Land-use maps for the fine domain for default case (AVHRR) and modified case (MODIS).
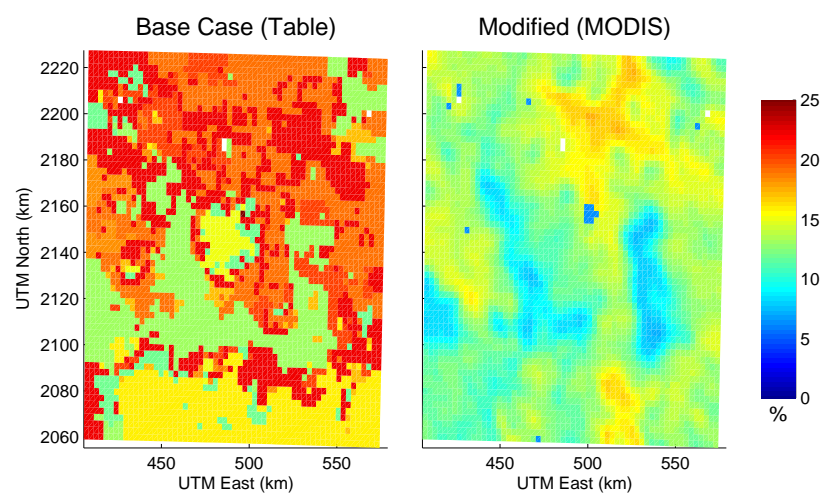

Fig. 5. Albedo maps for the fine domain with tabulated values (default case) and with MODIS values (modified case).

in the MODIS data. This has an impact on the stomatal resistance, see Sect. 6. Several areas were classified as savannah. This may need to be explored in the future, although the impact is limited to a larger value of the vapour pressure deficit function.

\subsection{Albedo}

Schaaf et al. (2002) obtain both black-sky and white-sky albedos from MODIS for seven spectral bands and 3 broad bands using the algorithms described by Lucht et al. (2000b). These are calculated every 16 days at a resolution of $1 \mathrm{~km}$, correcting for atmospheric distortions and the presence of clouds. Gridded values for MM5 were obtained from the albedos for the broadband in the range of 0.3 to $5.0 \mu \mathrm{m}$, using a diffuse light fraction of 0.2 and averaging to the model resolution. Maps from March and April 2003 were then averaged to a single map representative of MCMA-2003. Averaging in time lead to a spatial field with no missing data and smoother variation from cell to cell. This was also applied to the other satellite data fields.

Figure 5 shows the comparison between the albedos derived from the tabular values for the AVHRR land-use and
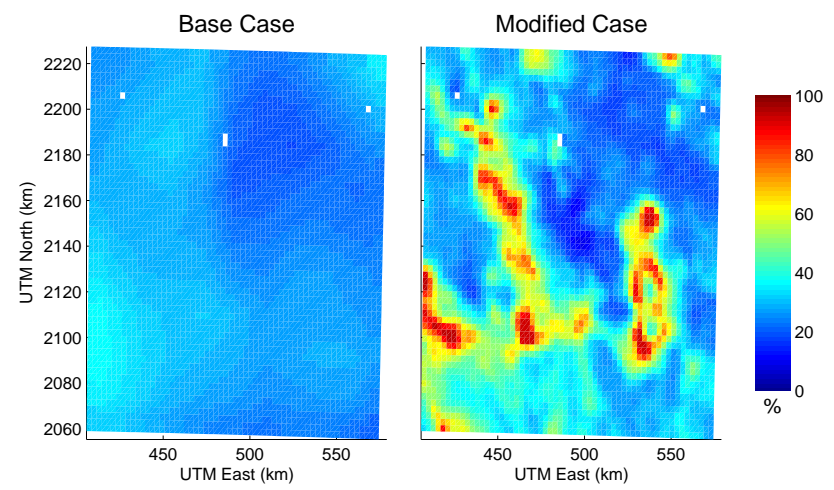

Fig. 6. Vegetation fraction maps for the fine domain for the default case (interpolated from coarse AVHRR data) and for the modified case (MODIS values).

the MODIS product. The MODIS values are lower for all categories. Forested areas in particular can be clearly seen. The urban areas have slightly lower albedos, but there is a smooth variation with the surrounding areas that corresponds with the differences in the urban fabric, ranging from builtup central areas, to dense low residential areas to the east or leafy residential to the southwest.

Liang et al. (2002) and Lucht et al. (2000a) found that the MODIS albedo products were within 0.02 of ground measurements, a precision deemed necessary for climate modelling. Tian et al. (2004) compared the values with those from the Community Land Model (CLM2) and attributed most of the discrepancy to model limitations rather than observation uncertainty.

\subsection{Vegetation fraction}

Vegetation fraction, by controlling evapo-transpiration, has a large impact on the latent heat flux. As for albedo, vegetation indices are calculated for 16 day periods at $1 \mathrm{~km}$ resolution (Huete et al., 2002). Vegetation fractions are derived from the normalised difference vegetation index (NDVI) using the method of Gutman and Ignatov (1998), exactly as was done with AVHRR data before.

By default, MM5 determines the vegetation fraction from monthly AVHRR values at $10 \min (18.5 \mathrm{~km})$ resolution. MODIS data are averaged from the three 16-day periods ending 22 March, 7 and 23 April. Figure 6 shows the comparison for the fine domain. The coarse resolution of the default data set fails to capture the detailed spatial patterns of the vegetation fraction. This is picked up very well in the high resolution data set, with forests on the mountains but the bare elevated volcano peaks clearly visible. The urban area has less vegetation but the variations in the different parts of the city are of the same magnitude as the variations with the surrounding areas - forest to the southwest, arid/agricultural to the east. 

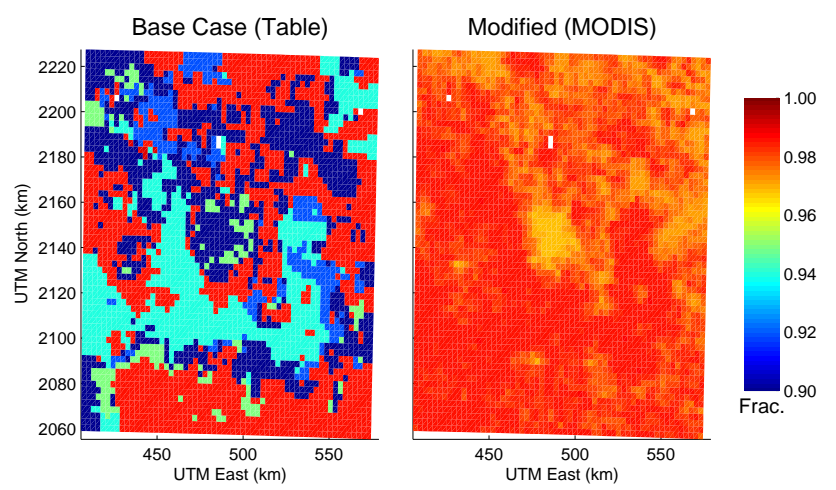

Fig. 7. Surface emissivity maps for the fine domain with tabulated values based on the AVHRR land-use map and with MODIS values.

\subsection{Surface emissivity}

Retrievals of surface emissivities in the thermal infra-red range from MODIS data are described in Petitcolin and Vermote (2002). MM5 requires the $9 \mu \mathrm{m}$ emissivity whereas MODIS has channels at 11 and $12 \mu \mathrm{m}$. The MODIS UCSB Emissivity Library contains a collection of spectral emissivities for a large number of reference surfaces. By looking at the wavelength dependence of these, it was decided to use the $11 \mu \mathrm{m}$ values. The emissivity product is calculated every 8 days. For this study, the periods ending 30 March, 7 and 15 April were averaged.

Figure 7 shows the comparison between the tabulated values and the MODIS maps. MODIS values are higher and vary much less than the table values. Some of the variation in the tabulated values, such as between grass and shrub land, seems to be an artefact of the land-use categories and is reduced in the MODIS data. Francis (2003) developed an atlas of surface emissivities and compared them with MODIS products. Similar discrepancies were found and were attributed to the limitations of the land-use categories rather than to the limitations of the satellite observations. Using such high emissivity values in MM5 however leads to an over estimation of the night time cooling causing a negative temperature bias and reduced winds. The satellite product was therefore not used in the model simulation, keeping instead the previous table values in combination with the MODIS land use categories. This issue will need to be explored further as the current simulation does have a warm bias at night but the satellite emissivities over-compensated in the present case. Higher spatial resolution data from the Advanced Spaceborne Thermal Emission and Reflection Radiometer (ASTER) has been compared with MODIS (Jacob et al., 2004) and could provide more detailed information on emissivities in the MCMA.

\subsection{Surface temperature}

Land-surface temperatures are obtained using the generalised split-window algorithm and screened for cloud effects (Wan et al., 2002). Quality assurance flags are provided with the data (Wan, 2003), indicating the uncertainty to be less than 1,2 or $3 \mathrm{~K}$ or higher. Wan et al. (2004) validated the data against field measurements to confirm these levels of accuracy. For the data retrievals above the MCMA, most of the data is within $1 \mathrm{~K}$ accuracy except for the urban area and certain other scattered pixels which are within $2 \mathrm{~K}$.

There are measurements four times a day from the night and day passes of the Terra and Aqua satellites. For the MCMA domain, the observations times are as follows: 22:00 to 23:00 for Terra night, 01:00 to 02:00 for Aqua night, 10:00 to 11:00 for Terra day and 13:00 to 14:00 for Aqua day (Central Standard Time). The land surface temperature retrieved from satellite corresponds to the skin temperature ("Ground T" in MM5). For modelling, we are interested in the deep-soil temperature. An empirical linear relationship between the deep soil temperature and the skin temperature was sought from the model output of the form:

$T_{\text {deep }}=a_{1} T_{1}+a_{2} T_{2}+a_{3} T_{3}+a_{4} T_{4}$

Where $T_{\text {deep }}$ is the deep-soil temperature, $T_{1}$ the surface temperature from the night pass of Terra, $T_{2}$ Aqua night, $T_{3}$ Terra day and $T_{4}$ Aqua day. MM5 was run for the same 10-day period twice with the final soil temperature from the first run used to initialise the second run, leading to a stable soil temperature profile. The linear relationship of the deep soil temperature to the skin temperature at the equivalent satellite overpass times was found by linear optimisation of the coefficients $a_{1}$ through $a_{4}$ to reduce the residual when applying Eq. (1) to every land grid cell in the domain. Separate coefficients were found for each domain: $(0.19,0.37,0.13,0.20)$ for domain $1,(0.24,0.35,0.14,0.08)$ for domain 2 and $(0.00,0.52,0.23,0.10)$ for domain 3 . Note that these were not constrained to sum to unity. Because deep soil temperature varies on the timescale of months, these were applied to average skin temperature obtained from the 98 -day periods from 6 March to 9 May 2003 in order to obtain an initial temperature field for MM5.

The initial temperature of the surface and of the first model layer was taken from the night pass of Aqua. Inspection of model output showed this to be a sufficiently good approximation that any errors would be transients of less than a day.

Initial soil temperatures in MM5 are interpolated from the GFS model output. A correction of $6.5 \mathrm{~K} / \mathrm{km}$ is then applied based on the height difference between the $1^{\circ}$ GFS grid and the MM5 grid. Figure 8 compares the deep-soil temperatures from the usual MM5 procedure with those obtained from MODIS for domain 1. The temperatures are similar along the coast but different at higher elevations, suggesting that the correction factor is too strong. Figure 9 shows the deep-soil temperatures for domain 3. The temperatures 


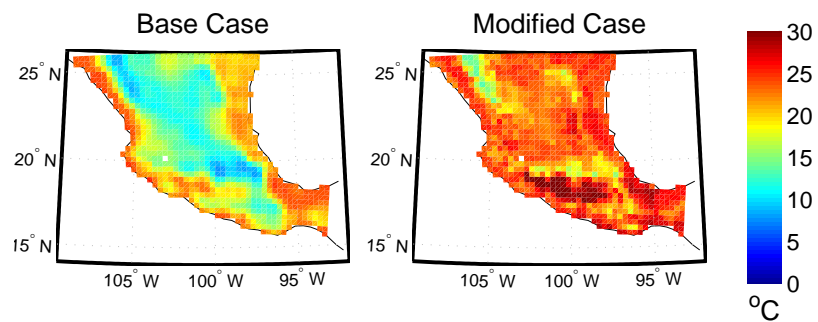

Fig. 8. Deep soil temperature maps for the coarse domain, default values and MODIS derived values.

are noticeably warmer over the whole domain, and the urban heat island can be seen for the MCMA, and to a lesser extent, for Toluca. Note however that this is a secondary factor in the simulations as the urban heat island is caused by properties of the surface materials and water availability among other things. The primary factor that is being addressed by obtaining a new deep soil temperature field is an improved estimate of the ground heat flux over the whole domain.

\section{Tabulated surface parameters}

The remaining surface parameters were specified by land-use and soil index tables in MM5. The MODIS land use maps were used for the modified case, but both cases used the same soil types from the UN-FAO database. The default values (Grell et al., 1995) were used except for four parameters for the urban land category only.

Surface roughness was recently increased in MM5 for the urban category from $50 \mathrm{~cm}$ to $80 \mathrm{~cm}$. The MCMA however has few high-rise buildings and is dominated by 2 -story buildings with flat roofs. They are dense, but form a relatively smooth and continuous surface. Grimmond and Oke (1999) reviewed the literature on surface roughness measurements. Based on their descriptions, it was decided that the surface roughness length would be better approximated by low to medium density urban categories, and a value of $25 \mathrm{~cm}$ was used.

The remaining parameters that were modified are: rooting depth, a parameter for the radiation stress function and a parameter for the vapour deficit function. These influence the latent heat fluxes. The default values are very different from the surrounding grid cells in the model and lead to low latent heat fluxes over the MCMA. As was seen from space for albedo and vegetation fraction, the variations in surface properties for the MCMA are gradual. The rooting depth was therefore increased to 3 layers, as for the other land-use categories. The radiation stress function parameter was set to 100 and the vapour deficit function parameter was set to 40 to bring them in to line with the surrounding area. The stomatal resistance, at $200 \mathrm{sm}^{-1}$, remains higher than the surrounding areas which vary from 40 for grassland to 170 for mixed grass and shrub land.
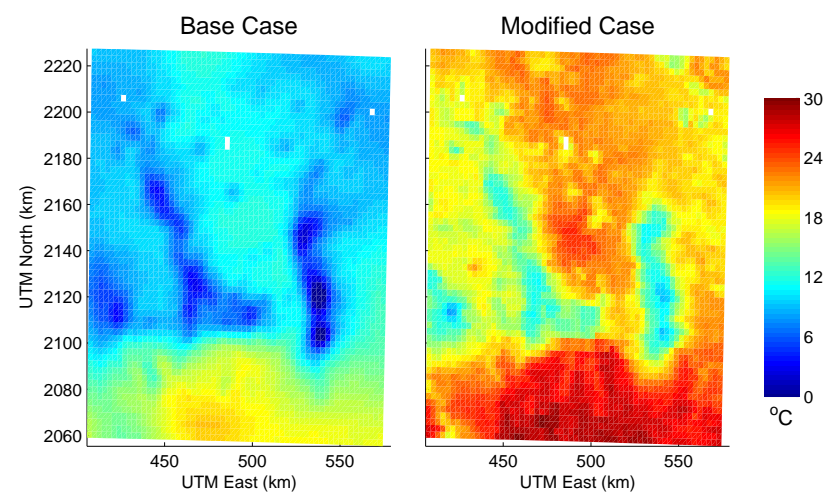

Fig. 9. Deep soil temperature maps for the fine domain, default values and MODIS derived values.

\section{Model results}

Two model simulations will be described here: the base case with model settings and input fields set to default values, and the modified case with the input fields specified as described above. Part of the motivation for the current study is that four dimensional data assimilation (FDDA) did not improve the simulations. Further tests were therefore performed with analysis nudging on the coarse grid for base and modified cases, in order to compare their performance for the fine domain with the modified case with no nudging. Simulations with the 5 layer soil model (but no nudging) were also compared for both the base and the modified case in order to show the improvements obtained from a more sophisticated land surface model.

The description of the results will focus on the NOAH soil model with no nudging as these gave the results closest to observations. Results will be shown for 15 April which is in the middle of the simulation period and has a well defined wind shift. The statistical evaluation however will show results from all 6 simulations using data from the complete 4-day simulation period.

\subsection{Synoptic overview}

14-17 April 2003 was described as an "O3-South" episode in de Foy et al. (2005). Figure 10 shows the high pressure system on the Pacific Coast of Mexico. This leads to subsidence over Mexico City and northerly winds aloft resulting in clear skies and weak winds in the basin. The corresponding surface winds in Fig. 11 show the competing effects of the sea breezes from the Pacific Ocean and the Gulf of Mexico, reinforced by northwesterly winds from Baja California and southeasterly ones in the Gulf. The convergence line is on the east side of the Mexican Plateau and passes through the Mexico City basin combining with the local basin winds to create rapid wind shifts. 


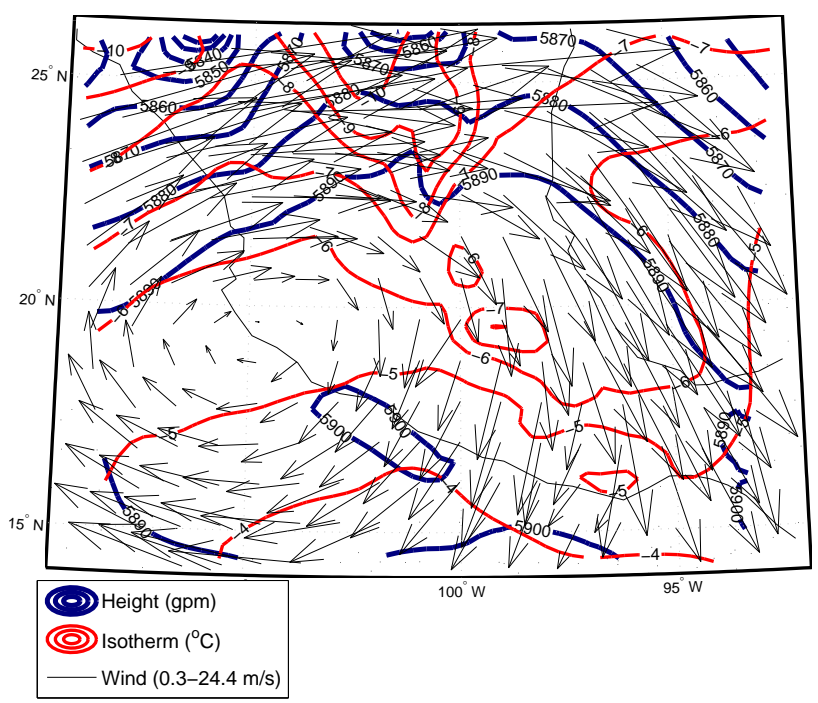

Fig. 10. Weather map at $500 \mathrm{hPa}$ for 15 April 2003, 19:00 CDT based on the MM5 coarse domain simulation for the modified case. Thick blue lines for $500 \mathrm{hPa}$ height, thin red lines for isotherms and wind vectors are shown. Alternate vectors shown only.

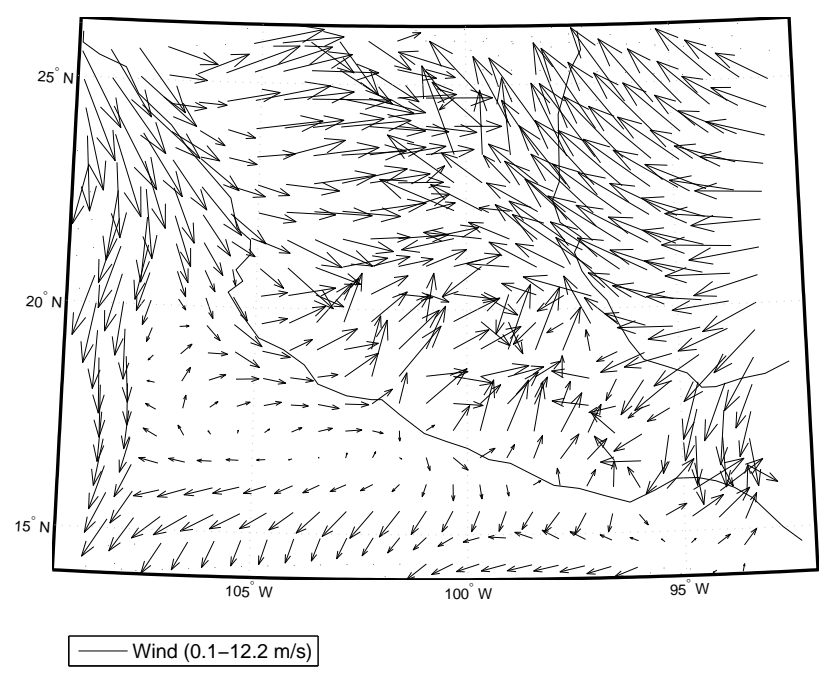

Fig. 11. Surface wind vectors for 15 April 2003, 19:00 CDT based on MM5 coarse domain simulation for the modified case. Alternate vectors shown only.

\subsection{Basin observations}

\subsubsection{Surface wind vectors}

Surface $(10 \mathrm{~m})$ wind vectors from the modified case are shown in Fig. 12 alongside all available observations in the basin. This shows the classic "O3-South" pattern. At 07:00 there are very weak winds in the basin with drainage flows into the basin around the perimeter. On the west and east are stronger channel flows over the mountain pass from Toluca
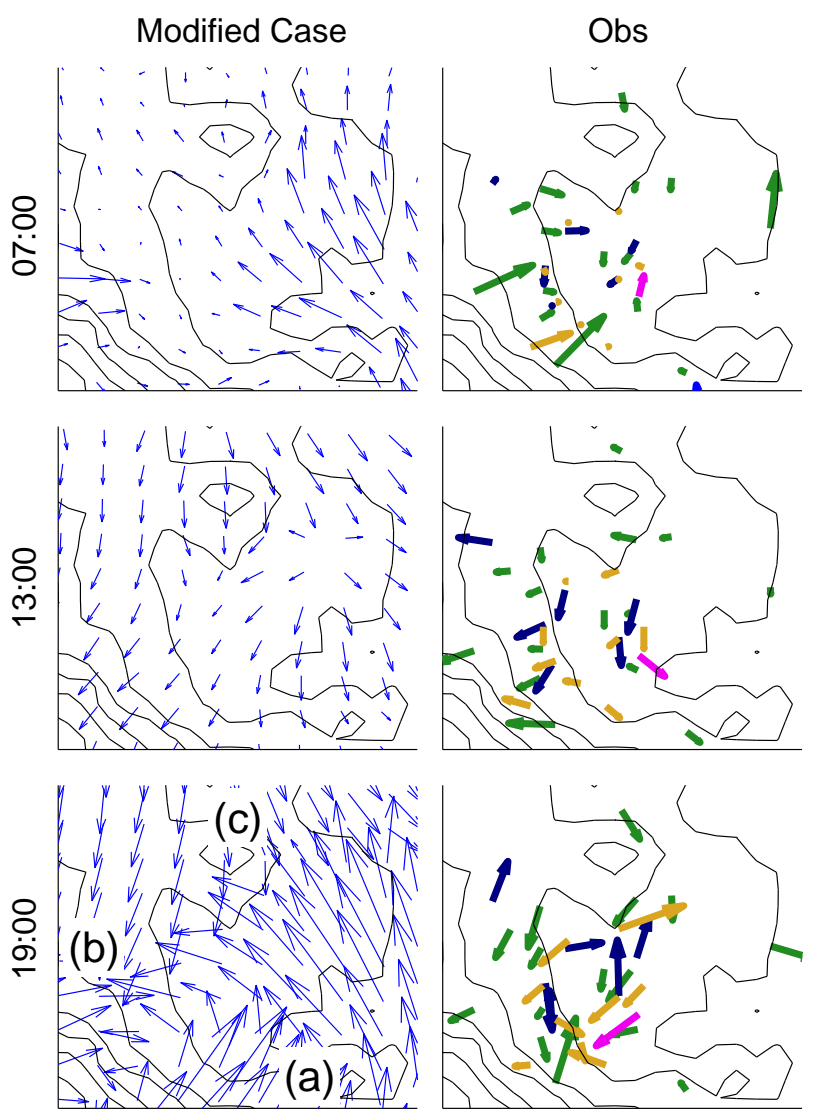

Fig. 12. Surface winds in the Mexico City basin for 15 April 2003, 07:00, 13:00 and 19:00 CDT. Model output with alternate vectors shown on the left. All available observations shown on the right. Contour lines of terrain elevation.

and through the Chalco passage which are residuals from the previous day's wind shift. At 13:00, there are upslope flows along the western and southern slopes of the basin leading to northerly flows in the whole basin, that become increasingly steady and strong. By 19:00, the jet flow from the Chalco passage has moved through the whole basin pushing back the convergence line to the north of the MCMA.

There is good qualitative agreement between the model and the measurements. Note the variability among the observations, which is a factor of the weak and variable basin winds on the one hand, and of very different siting conditions among stations and between different monitoring networks on the other. At 07:00, the model captures well the strong channel flows but does not do so well with the weak drainage flows in the northwest. At 13:00, the structure of the model winds is much more coherent, with the direction of the slope flows modified by the larger scale flows aloft. There is some surface divergence on the northeast side, which is due to convergence aloft from channelling of the winds by the mountains as they enter the basin. At 19:00, the convergence in the basin is strongly simulated by the model, with 


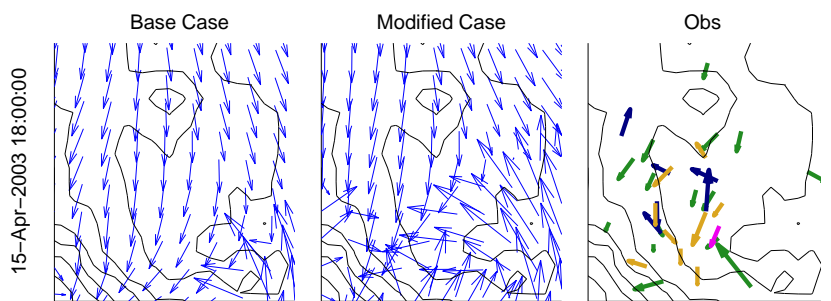

Fig. 13. Comparisons of surface winds in the Mexico City basin for 15 April 2003, 17:00 CDT, for the base case, modified case and observations. Alternated model vectors shown only.

the position of the convergence line too far to the north. The main features are well simulated however: strong southerly gap flow at Chalco (a), winds over the southwestern edge of the basin with channelling through the pass from Toluca (b) and northeasterly winds being pushed back in the northwest corner (c).

A comparison of the simulated wind convergence for the base case and the modified case is shown in Fig. 13 for 18:00 CDT. At this time the observations show the northeasterly flow in the basin and the advancing jet from the southeast. These features are present in both model simulations. The wind jet is however much less developed in the base case than in the modified case. There is some disagreement in wind direction between the different observations which make it difficult to place the actual position of the convergence. Furthermore, some stations are locally influenced. Santa Ana Tlacotenco (SATL) for example has up-slope winds whereas Tlahuac (TAH) sees the southeasterly jet. Taking these factors into account, the modified case can be seen to better represent the wind shift than the base case.

\subsubsection{Radiosonde observations}

Radiosondes were launched every $6 \mathrm{~h}$ during MCMA-2003 from GSMN (MEX) on the western slopes of the basin. Soundings for 15 April 2003 are shown in Fig. 14 for 07:00, 13:00 and 19:00 CDT along with model results for the base case and the modified case for both GSMN and CENICA.

In the morning, there is little difference between the cases and between the sites. The atmosphere is stable with some residual stratification in the temperature profile left over from the previous day's mixing layer. These are also reflected in the humidity profile, with a more humid layer up to $1250 \mathrm{~m}$ above ground level. The model both over-predicts this features and fails to mix it within the bottom layer. The winds are strong and northwesterly aloft. Below $3000 \mathrm{~m}$ they weaken and become more westerly with a pronounced surface jet in the bottom $750 \mathrm{~m}$. The model correctly simulates the winds aloft but they are too weak in the region shielded by topography. The model also fails to capture the downslope jet simulating a weak southwesterly drainage flow in-
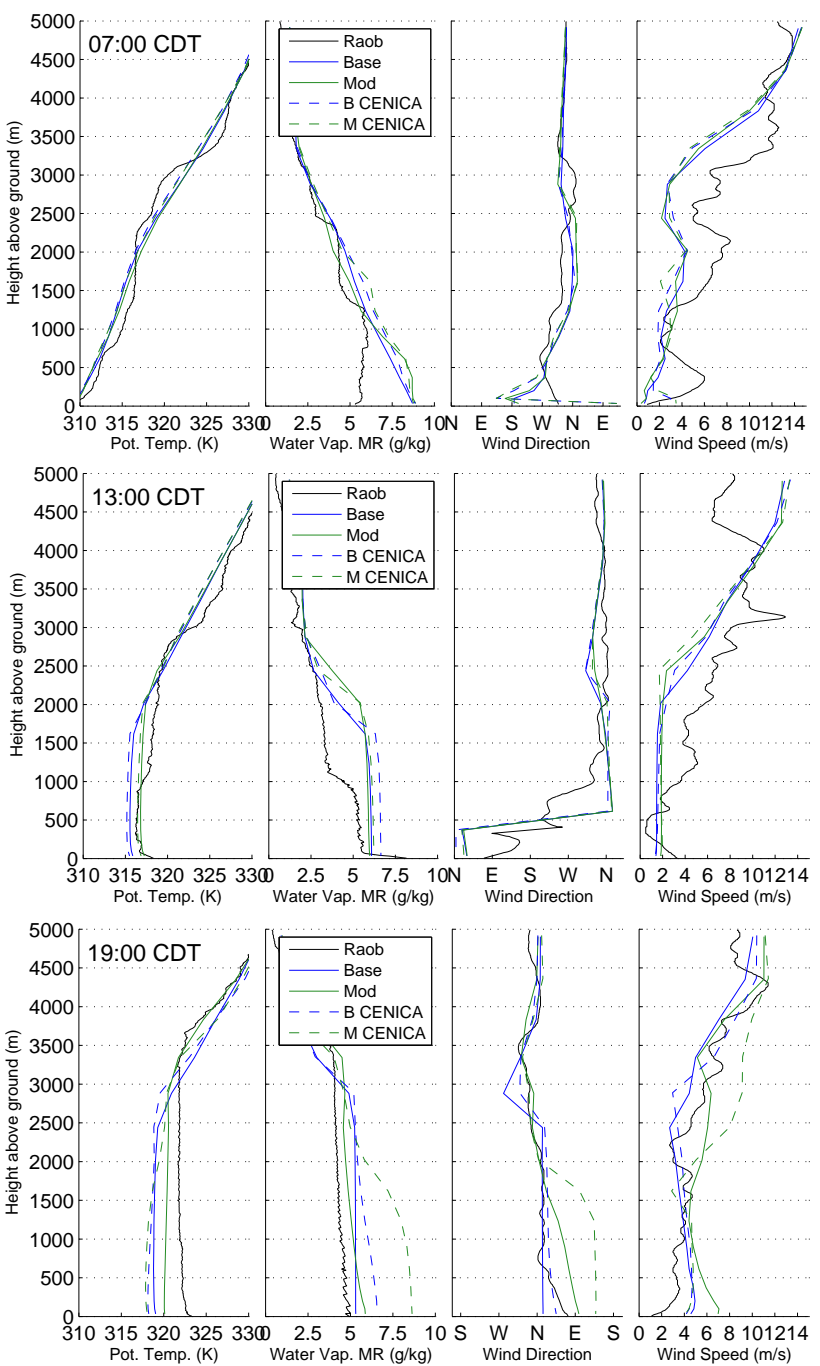

Fig. 14. Radiosonde profiles of temperature, humidity, wind direction and speed from GSMN (Mexico City, MEX, $2309 \mathrm{~m}$ a.s.1.) in thick black lines for 15 April 2003 at 07:00, 13:00 and 19:00 CDT. Thin lines are model simulations at GSMN, dotted lines at CENICA. Base case shown by blue lines, modified case shown by green lines.

stead. This is probably the reason for the moister and more stratified boundary layer.

By midday, the intense solar heating has led to a mixing layer reaching up to $3000 \mathrm{~m}$. This is uniform across both sites. The modified case is warmer in the mixing layer and matches very closely the observations, especially below $1000 \mathrm{~m}$. This is also the case for humidity, where the model matches well aloft and below $1000 \mathrm{~m}$ but the excess humidity from the morning is now mixed through to between 1500 and $2000 \mathrm{~m}$, nearly $1000 \mathrm{~m}$ higher than the observations. The winds are well represented although too weak in the bottom $2500 \mathrm{~m}$. The very low wind speeds observed explain the variable wind direction near the surface. When winds are 


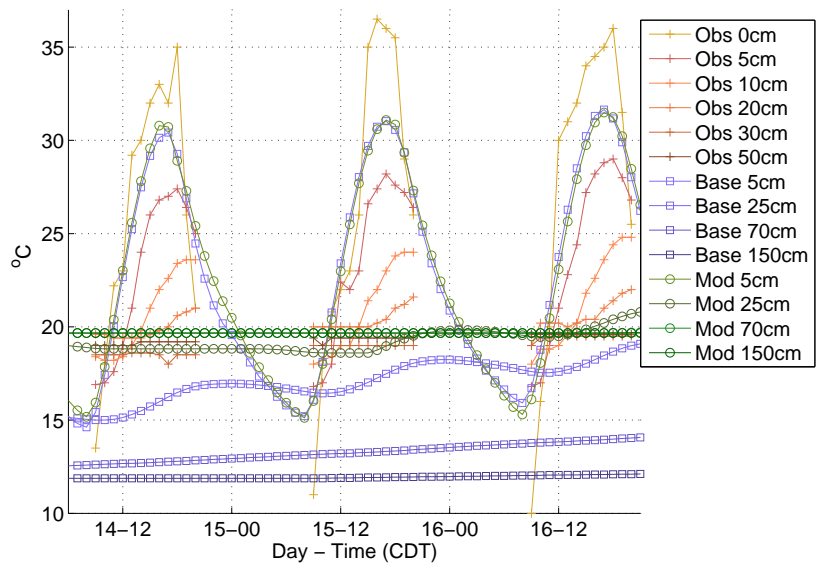

Fig. 15. Soil temperature measurements from Montecillo (09:0020:00 CDT) for 14-16 April 2003 in orange hues and crosses versus model results, base case in blues in squares, modified case in greens and circles for all depths/layers available.

this variable, grid and time-averaged model results $(3 \mathrm{~km}$ in space, $1 \mathrm{~h}$ in time) cannot be expected to match the wind direction.

The afternoon is when the largest differences between the model cases are expected as well as between the 2 sites. At 19:00, the boundary layer is $3500 \mathrm{~m}$ high as seen by both the temperature and humidity profiles. This is correctly simulated by the modified case. The base case is too cool with a mixing height of $3000 \mathrm{~m}$. At CENICA, the modified case is already experiencing an influx of moist air from the southeast jet. This wind shift is over-predicted at GSMN with the observations lying between the 2 cases. The wind speeds are now better represented and even too strong in the layer below $1000 \mathrm{~m}$.

\subsubsection{Surface time series}

Figure 15 shows the comparison of soil temperature measurements at Montecillo with the simulations. The NOAH soil model has 4 layers with thicknesses of 10, 30, 60 and $100 \mathrm{~cm}$. The prediction heights are the layer mid-points: 5 , $25,70,150 \mathrm{~cm}$. The cold bias of the base case can be clearly seen. There is a gradual warming of the soil which would need at least 5 days just for layer 2 to reach equilibrium, much more for the deeper layers. The modified case has a deep soil temperature nearly exactly as measured. The surface layer in the model lies between the observations for the $0 \mathrm{~m}$ and $5 \mathrm{~m}$ levels. For this grid point, both model cases are the same, although for other points the modified case is usually warmer by $2-3 \mathrm{~K}$ in the afternoon. In either cases, however, the ground heat flux is affected.

Time series of surface meteorological variables at CENICA follow a strong diurnal pattern, as shown in Fig. 16. The base case and modified case values are plotted next to the observations for the 4 days of simulation, using the $2 \mathrm{~m}$
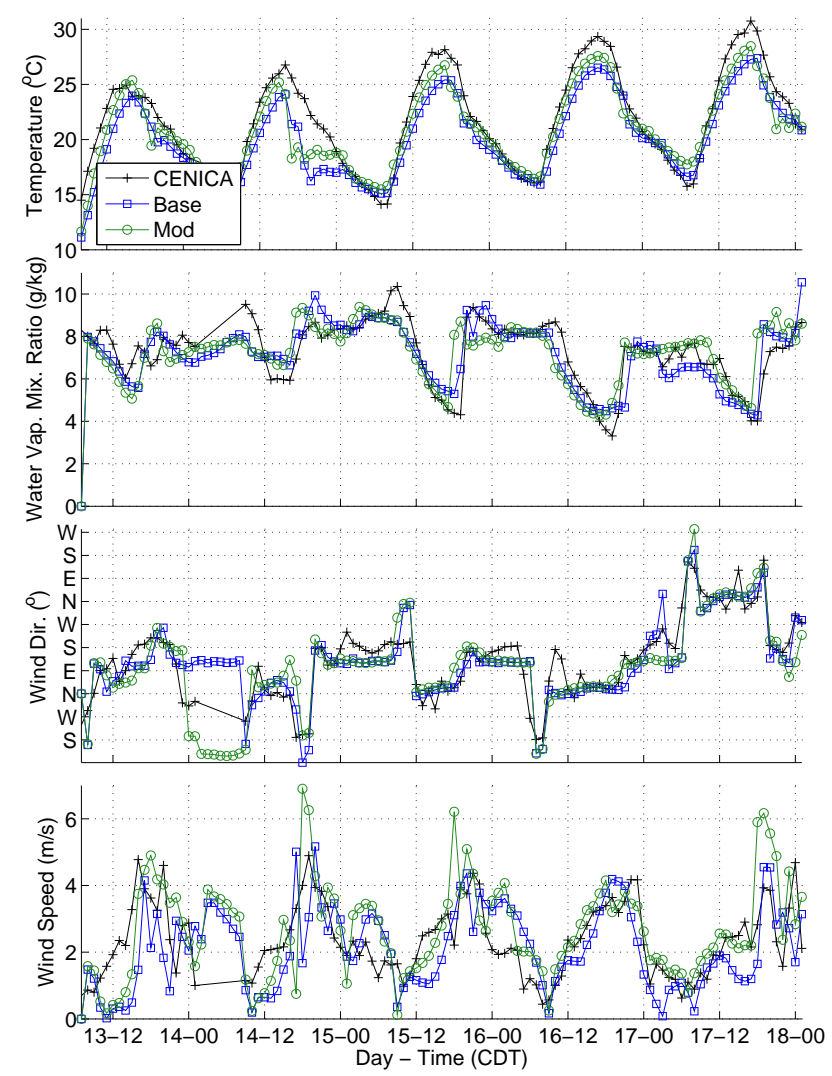

Fig. 16. Surface observations at CENICA in black versus base (blue) and modified (green) model cases for temperature, humidity, wind direction and wind speed. Entire simulation period shown: 13 April 07:00-18 April 00:00 CDT.

temperature and humidity values and the $10 \mathrm{~m}$ wind speed and direction. The temperature variation is well simulated although the afternoon peak has a cool bias in the model. This is reduced in the modified case. The humidity and wind direction profiles are very similar, with wind shifts leading to humidity shifts. Northerly winds bring dry air into the basin, and southerly ones lead to an influx of moist air. The timing of the shift can differ by 1 to $2 \mathrm{~h}$ between the base case and modified case. The wind speed in the basin follows a very regular pattern: minimum at sun-rise with winds less than $1 \mathrm{~m} / \mathrm{s}$, maximum at sun-set. This is very well represented by the model, especially after the initialisation period. The base case has minimum winds that are too calm with a delayed pick-up during the morning. This feature, crucial in determining pollutant dispersion in the MCMA, is much improved in the modified case.

\subsubsection{Urban heat island}

The final comparison of model simulations is for the skin temperature at 03:00 and 15:00, shown in Fig. 17 next to the MODIS data from the Aqua satellite passes for those days. The model simulations have a smaller range in diurnal skin 
temperature, with a warm bias at night and a cool one during the day. The urban heat island can be clearly seen at night but the afternoon temperatures are not affected as much, as has been observed for other cities (Atkinson, 2003). The base case has a very sharp transition between the rural and urban grid points. The modified case better represents the gradual nature of the heat island and also its greater spatial extent due to urban growth. During the day, the modified case better represents the heating up of the surface in the basin as well as on the plains to the north of the MCMA. There are sharper gradients between land-use classes in the satellite measurements and these are reflected in the modified case. Overall however, the improvements are modest. Further improvements could come from incorporating surface emissivities once the discrepancies between satellite sensing and known surface values are better understood. Refining soil moisture availability will also lead to more reliable simulations.

\section{Model statistics}

Having shown some of the model results versus observations, we will now present results on the statistical performance of the model. Given the large number of observations, reducing model performance to a handful of numbers is too simplistic and can be misleading. Taylor (2001) devised an elegant diagram to summarise model performance from different sources and/or simulations. However, these plots make it difficult to visualise bias which was an important consideration for this work, especially in relation to air quality modelling.

An alternative diagram was therefore sought that would display both error and bias while preserving the relationship to the standard deviation of the data. This was achieved by a two-dimensional plot with a point representing bias (Eq. (2), $P$ are model results, $O$ observations) versus centred root mean square error (RMSEc, i.e. RMSE with the bias component removed, Eq. (3)). A second point is plotted for the standard deviation of the model simulation versus the standard deviation of the data. All of these values have units that are the same as the observed variable. Ideally, the model variability captures the variability in the measurements which translates in the diagram as standard deviation points on the line $y=x$. The error point should be close to the origin representing low bias and low errors. The errors should also be lower than the variability of the data, suggesting that the error points should be to the left of the standard deviation point. Different criteria have been recommended for this, for example that errors should be less than $30 \%$ or $50 \%$ of the variability. This is however dependent on the variable being compared and the case being studied.

$$
B I A S=\bar{P}-\bar{O}
$$
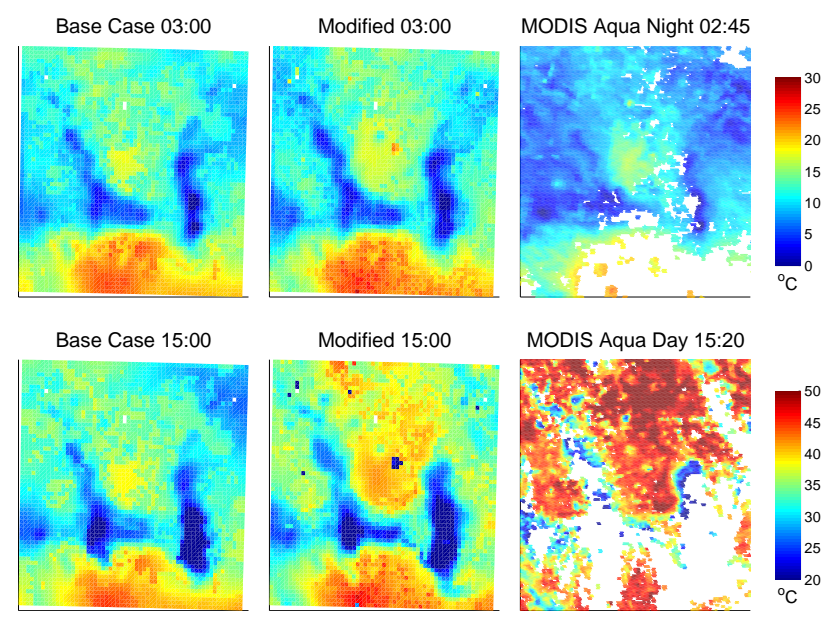

Fig. 17. Comparison of skin temperature for base (left) and modified (middle) cases with MODIS measurements (right) for AQUA night (top) and day (bottom) passes. Model results from 15 April 03:00 and 15:00 CDT. Remote sensing from AQUA overpass at 02:45 and 15:20 on the same day shown at sensor resolution.

$$
R M S E c=\left[N^{-1} \sum_{i=1}^{N}\left(\left(P_{i}-\bar{P}\right)-\left(O_{i}-\bar{O}\right)\right)^{2}\right]^{0.5}
$$

Figure 18 shows such a diagram for wind speed measurements from radiosonde soundings for the coarse domain. Each point represents the statistics for one sounding for one model case. In order to help interpret the cloud of points, ellipses are drawn for each model case centred on the average with radii representing the standard deviation. Elongated ellipses along the line $y=x$ for the standard deviation points show that the model variability is the same as the data. Ellipses centred on the x-axis for the error points show that the model does not have a net bias, but the errors are around $2 \mathrm{~m} / \mathrm{s}$, which is close to the variability of the data. The error reduction from using FDDA can be clearly seen. Because the statistics are calculated with the same data as the analysis, however, this shows that the algorithm worked but does not necessarily show that the simulation is improved.

The diagram for the fine domain comparing the simulations with the GSMN sounding shows a well represented variability with similar errors to the coarse domain. There are now greater differences between the cases as the land surface has a much bigger impact on the fine scale simulations. There is also an apparent trade-off between bias and error. The base case has a negative bias with winds too weak by nearly $1 \mathrm{~m} / \mathrm{s}$. This is eliminated in the modified case at the cost of slightly increased RMSEc. Both analysis nudging and the 5 layer soil model performed noticeably worse for the fine domain with larger RMSEc values. This shows that the use of a more sophisticated land surface model was justified, and furthermore that focusing on improved land surface 

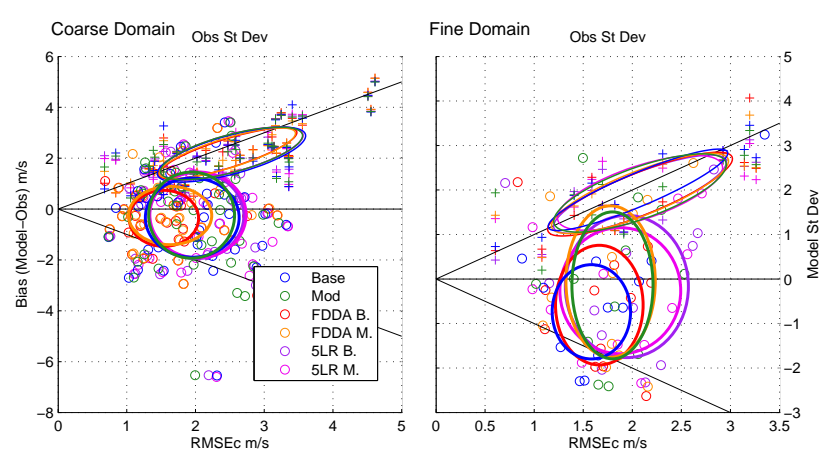

Fig. 18. Statistics diagram for radiosonde observations of wind speed for the coarse domain and the fine one for the first $4000 \mathrm{~m}$ above ground. Crosses represent the standard deviation of the simulation results versus that of the observations. Circles represent the bias versus the centred root mean square error $(R M S E c)$. Each model case is represented by a different colour, multiple symbols for each case represent statistics from individual sounding times and locations. Ellipses are drawn for each model case centred on the average of all the points and with radii corresponding to the standard deviation. For the error points, the ellipses show the average bias and error along with the variation between the soundings. For the standard deviation points, the ellipses are calculated along the $y=x$ line to show if there is a systematic difference in the standard deviation of the model and of the observations, and to show the scatter between soundings.

representation for the current case is a bigger factor in simulation improvement than analysis nudging.

Figure 19 shows similar diagrams for the surface temperature, wind speed and wind direction in the basin, using the data at CENICA and at SMN stations. The base case has a cold bias of around $1 \mathrm{~K}$ which is reduced but not eliminated in the modified case. The 5 layer model has much larger errors and bias. For wind speed, there is a negative bias of around $0.5 \mathrm{~m} / \mathrm{s}$ for the base case. This modified case has no bias but slightly higher errors. The RMSEc increased for only some of the stations however, leading to more uniform errors in the domain. The cases with analysis nudging and with the 5 layer soil model perform clearly worse although the impact of the satellite data shows a similar trend as for the base and modified cases. For wind direction, the picture is more mitigated with no improvement in the statistics. While the average bias is close to zero, the range among the stations is large and the errors are in excess of the variability of the data. This suggests that in addition to simulation improvements, more work will be needed in evaluating the wind direction performance.

One limitation of the evaluation is the comparison of model data with point radiosonde observations at very limited times and surface observations that may be locally influenced by the urban fabric and surrounding vegetation. Rife et al. (2004) examine the performance of mesoscale models at different spatial ranges. For basin flow, they find that
MM5 with fine resolution performs no better than regional models with much coarser grids even though it has a much better qualitative representation of the flow features. This is attributed to the importance of the subdiurnal range of the wind power-spectrum which consists of short-scale fluctuations that cannot be expected to be simulated by a model. This suggests a limit on the ability of models to represent point measurements as well as of statistical metrics to evaluate the model performance.

\section{Conclusions}

High resolution satellite observations of land surface parameters were used to simulate the wind circulation patterns in the Mexico City basin. The surface land use, albedo, vegetation fraction and surface temperature were specified from remote sensing measurements. This led to an improved simulation of the afternoon wind jet that clears the air in the MCMA and a more accurate determination of the mixing height which is a determining factor for pollution levels. The urban heat island was more accurately simulated, albeit slightly, showing its greater spatial extent at night than during the day and a varying intensity due to different land use patterns surrounding the city.

A novel plot was devised to analyse the statistical performance of the model compared to numerous observations. By preserving separate statistics for different stations, the diagram displays the variability in both measurements and model agreement, providing a context for the interpretation of the results and the evaluation of model improvements.

The present work seeks to reduce the uncertainty as well as the dependence on look-up tables for important surface parameters. The aim is to reduce the potential for compensating errors in model simulations so as to improve the understanding of the factors affecting the wind circulation in the basin. The extent to which the extra constraints lead to fewer uncertainties in the heat budget in the basin will need to be further explored. Discrepancies exist between surface based measurements and satellite derived data. This was particularly noticeable for emissivity values for which further evaluation will be required before inclusion into meteorological models. Use of alternate satellite sensors will be able to reduce uncertainty and expand the current analysis. For example, data from ASTER for soil temperature and surface emissivities is available at higher spatial resolution and would improve the understanding of urban impacts.

Sensitivity analyses on the parameters used in land surface models were carried out by Atkinson (2003) and Mölders (2001). Both studies suggest that the Bowen ratio is dependent on a range of parameters that are site- and studyspecific. In the present work, soil moisture remains the largest source of uncertainty, especially as no field measurements are available. Further work will need to better 

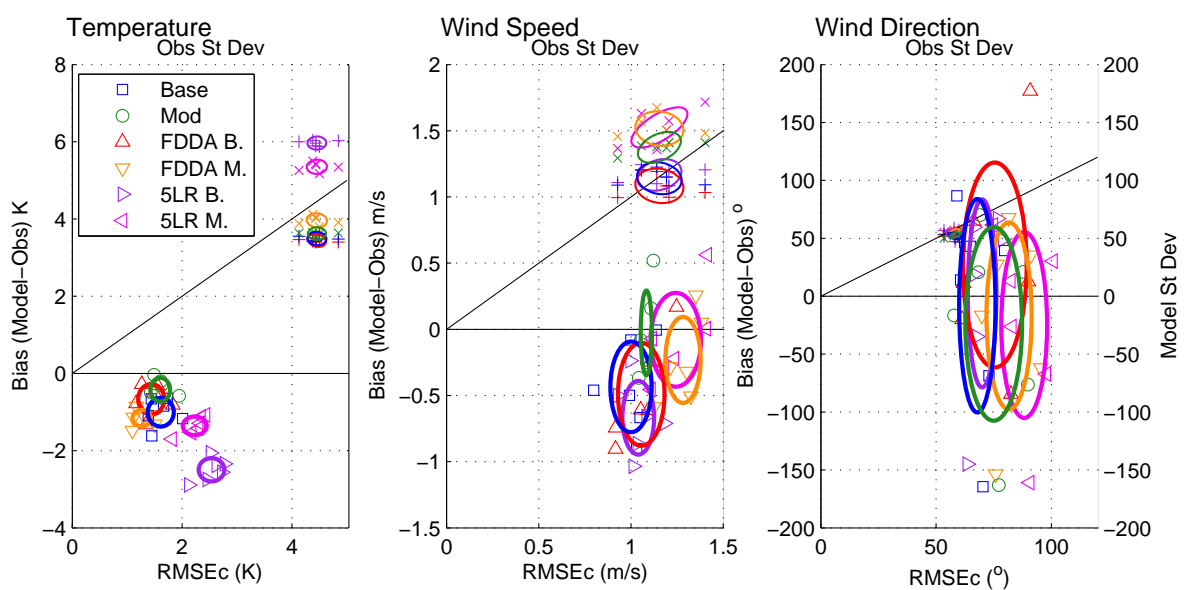

Fig. 19. Statistics diagram for surface observations of temperature, wind speed and wind direction for domain 3. See Fig. 18 for explanation. Colour coding is the same as for the radiosondes, but with different symbols for each series of error points and crosses for the standard deviation points (+ for base case, $\mathrm{x}$ for modified). Points with the same colour and symbol represent results from different stations for the same model case.

constrain this parameter in order to analyse the separate effects of the land surface properties.

Further use can be made of existing satellite data sets in refining the inputs to land surface models. For continuity and simplicity, vegetation fraction in this study was derived from NDVI. This could be changed to EVI which is a more sensitive indicator (Huete et al., 2002). At present, there is a single urban category in the model. Stefanov et al. (2001) use Landsat Thematic Mapper data to classify urban points into sub-categories, which could be added to mesoscale models (Zehnder, 2002). Landsat data could also be used to evaluate the sub-grid scale variability and introduce it into the land surface model. Different approaches for this in mesoscale models are reviewed in Mölders (2001) who found that it could have a significant impact, especially on soil moisture availability and the Bowen ratio.

Relationships between vegetation fraction and surface radiant temperature have been used to estimate soil moisture from AVHRR (Owen et al., 1998) and evaporative fractions from both AVHRR and MODIS (Venturini et al., 2004). Data from several satellites are combined with models to develop surface energy flux estimates on the fine urban scale $(\sim 10 \mathrm{~m})$ (Norman et al., 2003). This remains an open issue however, with extensive work on both satellite measurements (see for example the Hydrosphere State Mission (HYDROS), NASA Earth System Science Pathfinder) and data assimilation (Caparrini et al., 2003).

Recently there have been very detailed micrometeorological measurements of urban climates, see for example Grimmond et al. (2004). For Mexico City, Tejeda-Martinez and Jauregui-Ostos (2005) review existing heat budget measurements and Salcido et al. (2003) describe a database of turbulent parameters obtained from 3 sonic anemometers around the MCMA. Further data also exists for the MCMA-2003 campaign (de Foy et al., 2005). These data will be used to refine the analysis of the surface heat budget in the model, and in turn to analyse the driving forces of the Mexico City basin circulation.

Urban modules being developed for mesoscale applications are particularly data-hungry. Including as much data as possible from satellite measurements will provide necessary constraints on the model and help in their evaluation. This will enable more detailed analysis of processes involved in urban climates, for example the impact of anthropogenic heat fluxes and that of global radiation attenuation by aerosols (Jauregui and Luyando, 1999).

Acknowledgements. The analysis contained in this paper was made possible by the collaborative efforts of many people involved in field measurements, both during the campaign and over longer periods of time. We are indebted to the staff of CENICA who hosted the campaign and would like to thank B. Cárdenas, S. Blanco, A. Sanchez, O. Fentanes, J. Zaragoza, A. P. Ocampo, C. Cruz, C. Aguirre, R. Romo, A. Pino, R. Castañeda, R. Rodríguez, P. Escamilla as well as R. Ramos, A. Retama and the operators and analyst personnel of the "Red Automática de Monitoreo Atmosférico del Gobierno del Distrito Federal" for their contribution in administering and gathering the data used in this manuscript. We are grateful to M. Rosengaus, J. L. Razo, J. Olalde and P. García of the Mexican National Meteorological Service for providing the EHCA and Radiosonde data, to E. Caetano and V. Magaña for providing the data from the UNAM high school network, and to G. Pichardo for providing the soil temperature data.

MM5 is made publicly available and supported by the Mesoscale and Microscale Meteorology division at the National Center for Atmospheric Research. Their dedication and hard work is gratefully acknowledged. The satellite data used in this study were acquired as part of the NASA's Earth Science Enterprise. The algorithms were developed by the MODIS Science Teams. The data were processed by the MODIS Adaptive Processing System (MODAPS) and God- 
dard Distributed Active Archive Center (DAAC), and are archived and distributed by the Goddard DAAC.

We thank A. García and A. Jazcilevich of the Universidad Nacional Autónoma de México, A. Soler and F. Hernandez of the Secretaría del Medio Ambiente, Gobierno del Distrito Federal, México, A. Clappier, G. Carmichael and D. Entekhabi for helpful discussions, as well as P. Sheehy and two anonymous reviewers for valuable comments on the manuscript. The financial support of the Comisión Ambiental Metropolitana of Mexico, of the US Department of Energy (Award DE-FG02-05ER63980) and of the Molina Center for Strategic Studies in Energy and the Environment for this work is gratefully acknowledged.

Edited by: C. E. Kolb

\section{References}

Arnfield, A. J.: Two decades of urban climate research: A review of turbulence, exchanges of energy and water, and the urban heat island, Int. J. Climatology, 23, 1-26, 2003.

Atkinson, B. W.: Numerical modelling of urban heat-island intensity, Boundary-layer Meteorol., 109, 285-310, 2003.

Britter, R. E. and Hanna, S. R.: Flow and dispersion in urban areas, Ann. Rev. Fluid Mechanics, 35, 469-496, 2003.

Caparrini, F., Castelli, F., and Entekhabi, D.: Mapping of landatmosphere heat fluxes and surface parameters with remote sensing data, Boundary-layer Meteorol., 107, 605-633, 2003.

Carlson, T. N., Dodd, J. K., Benjamin, S. G., and Cooper, J. N.: Satellite estimation of the surface-energy balance, moisture availability and thermal inertia, J. Appl. Meteorol., 20, 67-87, 1981.

Cashion, J., Lakshmi, V., Bosch, D., and Jackson, T. J.: Microwave remote sensing of soil moisture: Evaluation of the TRMM microwave imager (TMI) satellite for the Little River Watershed Tifton, Georgia, Journal of Hydrology, 307, 242-253, 2005.

Chen, F. and Dudhia, J.: Coupling an advanced land surfacehydrology model with the Penn State-NCAR MM5 modeling system. Part I: Model implementation and sensitivity, Mon. Wea. Rev., 129, 569-585, 2001.

Crawford, T. M., Stensrud, D. J., Mora, F., Merchant, J. W., and Wetzel, P. J.: Value of incorporating satellite-derived land cover data in MM5/PLACE for simulating surface temperatures, J. Hydrometeorol., 2, 453-468, 2001.

Daley, R.: Atmospheric Data Analysis, Cambridge University Press, 1991.

de Foy, B., Caetano, E., Magaña, V. M., Zitácuaro, A., Cárdenas, B., Retama, A., Ramos, R., Molina, L. T., and Molina, M. J.: Mexico City basin wind circulation during the MCMA-2003 field campaign, Atmos. Chem. Phys., 5, 2267-2288, 2005.

Doran, J. C. and Zhong, S.: Thermally driven gap winds into the Mexico City basin, J. Appl. Meteorol., 39, 1330-1340, 2000.

Dousset, B. and Gourmelon, F.: Satellite multi-sensor data analysis of urban surface temperatures and landcover, Isprs J. Photogrammetry Remote Sensing, 58, 43-54, 2003.

Dudhia, J.: A multi-layer soil temperature model for MM5, in: Sixth PSU/NCAR Mesoscale Model Users' Workshop, 1996.

Dupont, S., Otte, T. L., and Ching, J. K. S.: Simulation of meteorological fields within and above urban and rural canopies with a mesoscale model (MM5), Boundary-layer Meteorol., 113, 111158, 2004.

Fast, J. D. and Zhong, S. Y.: Meteorological factors associated with inhomogeneous ozone concentrations within the Mexico City basin, J. Geophys. Res.-Atmos., 103, 18 927-18 946, 1998.

Francis, P. N.: The Development of an Infrared Land Surface Emissivity Atlas, and its Comparison with Modis/Terra Products, Tech. Rep. 405, UK MetOffice, 2003.

Friedl, M. A., McIver, D. K., Hodges, J. C. F., Zhang, X. Y., Muchoney, D., Strahler, A. H., Woodcock, C. E., Gopal, S., Schneider, A., Cooper, A., Baccini, A., Gao, F., and Schaaf, C.: Global land cover mapping from MODIS: algorithms and early results, Rem. Sens. Environ., 83, 287-302, 2002.

Grell, G. A., Dudhia, J., and Stauffer, D. R.: A Description of the Fifth-Generation Penn State/NCAR Mesoscale Model (MM5), Tech. Rep. NCAR/TN-398+STR, NCAR, 1995.

Grimmond, C. S. B. and Oke, T. R.: Aerodynamic properties of urban areas derived, from analysis of surface form, J. Appl. Meteorol., 38, 1262-1292, 1999.

Grimmond, C. S. B. and Oke, T. R.: Turbulent heat fluxes in urban areas: Observations and a local-scale urban meteorological parameterization scheme (LUMPS), J. Appl. Meteorol., 41, 792810, 2002.

Grimmond, C. S. B., Salmond, J. A., Oke, T. R., Offerle, B., and Lemonsu, A.: Flux and turbulence measurements at a densely built-up site in Marseille: Heat, mass (water and carbon dioxide), and momentum, J. Geophys. Res.-Atmos., 109, doi:10.1029/2004JD004936, 2004.

Gutman, G. and Ignatov, A.: The derivation of the green vegetation fraction from NOAA/AVHRR data for use in numerical weather prediction models, Int. J. Rem. Sens., 19, 1533-1543, 1998.

Hafner, J. and Kidder, S. Q.: Urban heat island modeling in conjunction with satellite-derived surface/soil parameters, J. Appl. Meteorol., 38, 448-465, 1999.

Hirabayashi, Y., Oki, T., Kanae, S., and Musiake, K.: Application of satellite-derived surface soil moisture data to simulating seasonal precipitation by a simple soil moisture transfer method, J. Hydrometeorol., 4, 929-943, 2003.

Hogue, T. S., Bastidas, L., Gupta, H., Sorooshian, S., Mitchell, K., and Emmerich, W.: Evaluation and transferability of the Noah land surface model in semiarid environments, J. Hydrometeorol., 6, 68-84, 2005.

Huete, A., Didan, K., Miura, T., Rodriguez, E. P., Gao, X., and Ferreira, L. G.: Overview of the radiometric and biophysical performance of the MODIS vegetation indices, Rem. Sens. Environ., 83, 195-213, 2002.

Jacob, F., Petitcolin, F., Schmugge, T., Vermote, E., French, A., and Ogawa, K.: Comparison of land surface emissivity and radiometric temperature derived from MODIS and ASTER sensors, Rem. Sens. Environ., 90, 137-152, 2004.

Jauregui, E. and Luyando, E.: Global radiation attenuation by air pollution and its effects on the thermal climate in Mexico City, Int. J. Climatol., 19, 683-694, 1999.

Jauregui, E. and Tejeda, A.: Urban-rural humidity contrasts in Mexico City, Int. J. Climatol., 17, 187-196, 1997.

Jin, M. and Shepherd, J. M.: Inclusion of urban landscape in a climate model - How can satellite data help?, Bull. Am. Meteorol. Soc., 86, 681-689, 2005.

Kalnay, E., Kanamitsu, M., and Baker, W. E.: Global numerical 
weather prediction at the national-meteorological-center, Bull. Am. Meteorol. Soc., 71, 1410-1428, 1990.

Kurkowski, N. P., Stensrud, D. J., and Baldwin, M. E.: Assessment of implementing satellite-derived land cover data in the Eta model, Wea. Forecast., 18, 404-416, 2003.

Liang, S. L., Fang, H. L., Chen, M. Z., Shuey, C. J., Walthall, C., Daughtry, C., Morisette, J., Schaaf, C., and Strahler, A.: Validating MODIS land surface reflectance and albedo products: methods and preliminary results, Rem. Sens. Environ., 83, 149-162, 2002.

Loveland, T. R., Reed, B. C., Brown, J. F., Ohlen, D. O., Zhu, Z., Yang, L., and Merchant, J. W.: Development of a global land cover characteristics database and IGBP DISCover from $1 \mathrm{~km}$ AVHRR data, Int. J. Rem. Sens., 21, 1303-1330, 2000.

Lucht, W., Hyman, A. H., Strahler, A. H., Barnsley, M. J., Hobson, P., and Muller, J. P.: A comparison of satellite-derived spectral albedos to ground-based broadband albedo measurements modeled to satellite spatial scale for a semidesert landscape, Rem. Sens. Environ., 74, 85-98, 2000a.

Lucht, W., Schaaf, C. B., and Strahler, A. H.: An algorithm for the retrieval of albedo from space using semiempirical BRDF models, Ieee Transactions On Geosci. Rem. Sens., 38, 977-998, $2000 \mathrm{~b}$

Margulis, S. A. and Entekhabi, D.: Variational assimilation of radiometric surface temperature and reference-level micrometeorology into a model of the atmospheric boundary layer and land surface, Mon. Wea. Rev., 131, 1272-1288, 2003.

Martilli, A., Clappier, A., and Rotach, M. W.: An urban surface exchange parameterisation for mesoscale models, Boundary-Layer Meteorol., 104, 261-304, 2002.

Matsui, T., Lakshmi, V., and Small, E. E.: The effects of satellite-derived vegetation cover variability on simulated landatmosphere interactions in the NAMS, J. Climate, 18, 21-40, 2005.

Mölders, N.: On the uncertainty in mesoscale modeling caused by surface parameters, Meteorol. Atmos. Phys., 76, 119-141, 2001.

Molina, L. T. and Molina, M. J. (Eds): Air Quality in the Mexico Megacity, Kluwer Academic Publishers, 2002.

Njoku, E. G., Jackson, T. J., Lakshmi, V., Chan, T. K., and Nghiem, S. V.: Soil moisture retrieval from AMSR-E, IEEE T. Geosci. Rem., 41, 215-229, 2003.

Norman, J. M., Anderson, M. C., Kustas, W. P., French, A. N., Mecikalski, J., Torn, R., Diak, G. R., Schmugge, T. J., and Tanner, B. C. W.: Remote sensing of surface energy fluxes at 10(1)-m pixel resolutions, Water Resour. Res., 39, 8, 1221, doi:10.1029/2002WR001775, 2003.

Oke, T. R., Spronken-Smith, R. A., Jauregui, E., and Grimmond, C. S. B.: The energy balance of central Mexico City during the dry season, Atmos. Environ., 33, 3919-3930, 1999.

Otte, T. L., Lacser, A., Dupont, S., and Ching, J. K. S.: Implementation of an urban canopy parameterization in a mesoscale meteorological model, J. Appl. Meteorol., 43, 1648-1665, 2004.

Owen, T. W., Carlson, T. N., and Gillies, R. R.: An assessment of satellite remotely-sensed land cover parameters in quantitatively describing the climatic effect of urbanization, Int. J. Rem. Sens., 19, 1663-1681, 1998.

Petitcolin, F. and Vermote, E.: Land surface reflectance, emissivity and temperature from MODIS middle and thermal infrared data, Rem. Sens. Environ., 83, 112-134, 2002.
Reichle, R. H., Koster, R. D., Dong, J. R., and Berg, A. A.: Global soil moisture from satellite observations, land surface models, and ground data: Implications for data assimilation, J. Hydrometeorol., 5, 430-442, 2004

Rife, D. L., Davis, C. A., Liu, Y. B., and Warner, T. T.: Predictability of low-level winds by mesoscale meteorological models, Mon. Wea. Rev., 132, 2553-2569, 2004.

Salcido, A., Celada-Murillo, A. T., Villegas-Martinez, R., SalasOviedo, H., Sozzi, R., and Georgiadis, T.: A micrometeorological data base for the Mexico City Metropolitan Area, Nuovo Cimento Della Societa Italiana Di Fisica C-geophysics Space Phys., 26, 317-355, 2003.

Schaaf, C. B., Gao, F., Strahler, A. H., Lucht, W., Li, X. W., Tsang, T., Strugnell, N. C., Zhang, X. Y., Jin, Y. F., Muller, J. P., Lewis, P., Barnsley, M., Hobson, P., Disney, M., Roberts, G., Dunderdale, M., Doll, C., d'Entremont, R. P., Hu, B. X., Liang, S. L., Privette, J. L., and Roy, D.: First operational BRDF, albedo nadir reflectance products from MODIS, Rem. Sens. Environ., $83,135-148,2002$

Schaake, J. C., Duan, Q. Y., Koren, V., Mitchell, K. E., Houser, P. R., Wood, E. F., Robock, A., Lettenmaier, D. P., Lohmann, D., Cosgrove, B., Sheffield, J., Luo, L. F., Higgins, R. W., Pinker, R. T., and Tarpley, J. D.: An intercomparison of soil moisture fields in the North American land data assimilation system (NLDAS), J. Geophys. Res.-Atmos., 109, doi:10.1029/2002JD003309, 2004.

Small, E. E. and Kurc, S. A.: Tight coupling between soil moisture and the surface radiation budget in semiarid environments: Implications for land-atmosphere interactions, Water Resour. Res., 39, 10, 1278, doi:10.1029/2002WR001297, 2003.

Stauffer, D. R. and Seaman, N. L.: Multiscale 4-dimensional data assimilation, J. Appl. Meteorol., 33, 416-434, 1994.

Stefanov, W. L., Ramsey, M. S., and Christensen, P. R.: Monitoring urban land cover change: An expert system approach to land cover classification of semiarid to arid urban centers, Rem. Sens. Environ., 77, 173-185, 2001.

Taylor, K. E.: Summarizing multiple aspects of model performance in a single diagram., J. Geophys. Res.-Atmos., 106, 7183-7192, 2001.

Tejeda-Martinez, A. and Jauregui-Ostos, E.: Surface energy balance measurements in the Mexico City region: a review, Atmosfera, 18, 1-23, 2005.

Tian, Y., Dickinson, R. E., Zhou, L., Myneni, R. B., Friedl, M., Schaaf, C. B., Carroll, M., and Gao, F.: Land boundary conditions from MODIS data and consequences for the albedo of a climate model, Geophys. Res. Lett., 31, L05504, doi:10.1029/2003GL019104, 2004

Townshend, J. R. G. and Justice, C. O.: Towards operational monitoring of terrestrial systems by moderate-resolution remote sensing, Rem. Sens. Environ., 83, 351-359, 2002.

van den Hurk, B.: Energy balance based surface flux estimation from satellite data, and its application for surface moisture assimilation, Meteorol. Atmos. Phys., 76, 43-52, 2001.

Venturini, V., Bisht, G., Islam, S., and Jiang, L.: Comparison of evaporative fractions estimated from AVHRR and MODIS sensors over South Florida, Rem. Sens. Environ., 93, 77-86, 2004.

Voogt, J. A. and Oke, T. R.: Thermal remote sensing of urban climates, Rem. Sens. Environ., 86, 370-384, 2003. 
Wan, Z., Zhang, Y., Zhang, Q., and Li, Z. L.: Quality assessment and validation of the MODIS global land surface temperature, Int. J. Rem. Sens., 25, 261-274, 2004.

Wan, Z. M.: MODIS Land Surface Temperature Products Users' Guide, Tech. Rep. (Web), Institute for Computational Earth System Science, University of California, Santa Barbara, 2003.

Wan, Z. M., Zhang, Y. L., Zhang, Q. C., and Li, Z. L.: Validation of the land-surface temperature products retrieved from Terra Moderate Resolution Imaging Spectroradiometer data, Rem. Sens. Environ., 83, 163-180, 2002.
Whiteman, C. D., Zhong, S., Bian, X., Fast, J. D., and Doran, J. C.: Boundary layer evolution and regional-scale diurnal circulations over the Mexico Basin and Mexican Plateau, J. Geophys. Res.Atmos., 105, 10 081-10 102, 2000.

Zängl, G., Chimani, B., and Häberli, C.: Numerical Simulations of the Foehn in the Rhine Valley on 24 October 1999 (MAP IOP 10), Mon. Wea. Rev., 132, 368-389, 2004.

Zehnder, J. A.: Simple modifications to improve fifth-generation Pennsylvania State University-National Center for Atmospheric Research Mesoscale Model performance for the Phoenix, Arizona, metropolitan area, J. Appl. Meteorol., 41, 971-979, 2002. 